\title{
Call for Papers, Issue 5/2021
}

\section{Process Mining at the Enterprise Level}

\author{
Jan vom Brocke $\cdot$ Mieke Jans $\cdot$ Jan Mendling $\cdot$ Hajo A. Reijers
}

Published online: 27 January 2020

(c) Springer Fachmedien Wiesbaden GmbH, ein Teil von Springer Nature 2020

\section{Special Issue}

Process Mining is a novel technology that helps enterprises to better understand their business processes. Over the last 20 years, there has been intensive research into various process mining techniques. These techniques support the automatic discovery of business process models from event $\log$ data, the checking of conformance between specified and observed behavior, the identification of various variants of a business process, non-compliant behavior, performance-relevant insights, and so forth.

Research on process mining has mostly focused on devising new or better algorithms (see van der Aalst 2016; Augusto et al. 2019). There are a few exceptions, among others the following. Van der Aalst et al. (2007) were the first ones to discuss process mining from the perspective of applications in industrial practice. Jans et al. (2014) applied process mining techniques to enrich audit evidence during a financial statement audit. Vom Brocke and Mendling (2018) present various applications of process mining in hospitals, insurances, software usability analysis, and logistics.

J. vom Brocke

University of Liechtenstein, Vaduz, Liechtenstein

M. Jans

Hasselt University, Hasselt, Belgium

J. Mendling ( $\square)$

Vienna University of Economics and Business, Vienna, Austria

e-mail: jan.mendling@wu.ac.at

H. A. Reijers

Utrecht University, Utrecht, The Netherlands
In recent years, process mining has found its way into enterprise software (Dumas et al. 2018), and has, thus, become available for companies in their daily practice of business process management. Companies like Celonis, Fluxicon, Signavio, and Software AG are among the roughly 20 companies that Gartner monitors. Kerremans (2019) from Gartner identifies business process improvement, auditing and compliance, process automation, digital transformation, and IT operations (in order of decreasing importance) as practical use cases for process mining in enterprise settings.

Some contributions have been made towards understanding process mining from an enterprise perspective. For instance, van Eck et al. (2015) and Aguirre et al. (2017) describe methodologies how process mining projects can be conducted and Maruster and van Beest (2009) provide a methodology how business processes can be redesigned with the help of process mining. Examples of domainspecific proposals in healthcare are Rebuge and Ferreira (2012) and Fernández-Llatas et al. (2015). Grisold et al. (2020) have introduced process mining as a strategy of inquiry to study in organizational science and to study organizational change in specific. Mans et al. (2013) have identified success factors for process mining projects. However, what is largely missing so far is research on how enterprises adopt process mining technology and how they integrate it into their information systems landscape.

\section{Invited Contributions}

The ambition behind this special issue is to fill the described research gap. We invite original contributions that investigate how enterprises actually adopt and use process mining software. We are specifically interested in 
submissions that make use of the extensive set of theories that have been discussed in information systems research and organizational science. These contributions are expected to utilize empirical research methods such as case studies, surveys, experiments (to name but a few) towards leveraging insights into how and why enterprises succeed or fail when adopting and using process mining software.

Topics that are welcomed include, but are not limited to the following:

- How is process mining used and adopted at the enterprise level?

- What is the potential of using various types of data in process mining?

- How does process mining complement other approaches and technologies?

- How do enterprises build suitable data sets?

- What are the implications for management of using process mining?

- Which governance structures do enterprises develop for process mining?

- How do enterprises calculate the business case of process mining?

- How does process mining change organizational culture?

- How does process mining change the required skill sets of tool users?

- How is process mining integrated into the IT landscape?

- How is process mining integrated with existing business process methodologies?

- How is process mining adopted in specific application domains, e.g., accounting, health, finance, HR, tax, etc.?

- How is process mining used to support digital transformation initiatives?

- What strategic implications for enterprises emerge from process mining usage?

- What is the business impact of adopting process mining?

- What is the overall business value of process mining?

- What is the transformative nature of process mining at the enterprise level?

- etc.

\section{Submission Guidelines}

Please submit papers by 1 Nov 2020 at the latest via the journal's online submission system (http://www.editor ialmanager.com/buis/). Please observe the instructions regarding the format and size of contributions to Business \& Information Systems Engineering (BISE). Papers should adhere to the general BISE author guidelines (http://www. bise-journal.com/author_guidelines).

All papers will be reviewed anonymously (double-blind process) by at least two referees with regard to relevance, originality, and research quality. In addition to the editors of the journal, including those of this special focus, distinguished international scholars will be involved in the review process.

\section{Schedule}

\begin{tabular}{|c|c|}
\hline $\begin{array}{l}\text { Submission } \\
\text { Deadline }\end{array}$ & 01 Nov 2020 \\
\hline $\begin{array}{l}\text { Author } \\
\text { Notification }\end{array}$ & 106 Jan 2021 \\
\hline $\begin{array}{l}\text { Completion } \\
\text { Revision }\end{array}$ & 101 March 2021 \\
\hline $\begin{array}{l}\text { Author } \\
\text { Notification }\end{array}$ & 215 April 2021 \\
\hline $\begin{array}{l}\text { Completion } \\
\text { Revision }\end{array}$ & 222 May 2021 \\
\hline $\begin{array}{l}\text { Final Workshop } \\
\text { Meeting }\end{array}$ & $\begin{array}{l}\text { with ECIS } 2021 \text { in Timisoara, Romania } \\
\text { (mandatory of acceptance candidates) }\end{array}$ \\
\hline
\end{tabular}

\section{References}

Aguirre S, Parra C, Sepúlveda M (2017) Methodological proposal for process mining projects. Int $\mathrm{J}$ Bus Process Integr Manag $8(2): 102-113$

Augusto A, Conforti R, Dumas M, La Rosa M, Maggi FM, Marrella A, Mecella M, Soo A (2019) Automated discovery of process models from event logs: review and benchmark. IEEE Trans Knowl Data Eng 31(4):686-705

Dumas M, La Rosa M, Mendling J, Reijers HA (2018) Fundamentals of business process management, 2nd edn. Springer, Heidelberg

Fernández-Llatas C, Lizondo A, Monton E, Benedí J-M, Traver V (2015) Process mining methodology for health process tracking using real-time indoor location systems. Sensors 15(12):29821-29840

Grisold T, Wurm B, Mendling J, vom Brocke J (2020) Using process mining to support theorizing about change in organizations. In: Proceedings HICSS 2020

Jans M, Alles MG, Vasarhelyi MA (2014) A field study on the use of process mining of event $\operatorname{logs}$ as an analytical procedure in auditing. Account Rev 89(5):1751-1773

Kerremans M (2019) Market guide for process mining. Gartner Report

Mans R, Reijers HA, Berends H, Bandara W, Prince R (2013) Business process mining success. In: Proceedings ECIS 2013, pp 89 ff

Maruster L, van Beest NRTP (2009) Redesigning business processes: a methodology based on simulation and process mining techniques. Knowl Inf Syst 21(3):267-297

Rebuge A, Ferreira DR (2012) Business process analysis in healthcare environments: a methodology based on process mining. Inf Syst 37(2):99-116

van der Aalst WMP (2016) Process mining-data science in action, 2nd edn. Springer, Heidelberg 
van der Aalst WMP, Reijers HA, Weijters AJMM, van Dongen BF, Alves de Medeiros AK, Song M, Verbeek HMW (2007) Business process mining: an industrial application. Inf Syst 32(5):713-732

van Eck ML, Lu X, Leemans SJJ, van der Aalst WMP (2015) PM $^{2}$ : a process mining project methodology. In: Proceedings CAiSE 2015, pp 297-313 vom Brocke J, Mendling J (2018) Business process management cases, digital innovation and business transformation in practice. Springer, Heidelberg 